Article

\title{
How Do Internet Enterprises Obtain Sustainable Development of Organizational Ecology? A Case Study of LeEco Using Institutional Logic Theory
}

\author{
Hao Ren ${ }^{1}$, Rongrong Wang ${ }^{1}$, Suopeng Zhang ${ }^{1, *}$ and An Zhang ${ }^{2, *}$ \\ 1 School of Economics and Management, Beihang University, Beijing 100191, China; \\ renhao@buaa.edu.cn (H.R.); 09484@buaa.edu.cn (R.W.) \\ 2 State Key Laboratory of Resources and Environmental Information System, Institute of Geographical \\ Sciences and Natural Resources Research, Chinese Academy of Sciences, Beijing 100101, China \\ * Correspondence: zhangsuopeng@buaa.edu.cn (S.Z.); Zhangan@igsnrr.ac.cn (A.Z.)
}

Received: 26 June 2017; Accepted: 31 July 2017; Published: 4 August 2017

\begin{abstract}
This study explores how Internet enterprises integrate different industries to sustainably develop organizational ecology, using institutional logic theory and an exploratory case study of LeEco, a famous Chinese Internet enterprise. The findings are as follows: (1) There are two main barriers to sustainable development of internal organizational ecology: resource barriers and information barriers. To overcome these obstacles, managers should carry out a series of institutional practices so that the organizational ecology obtains both product and institutional legitimacy; (2) A new institutional practice, the rigid/flexible method, is proposed, which includes implementation, communication, incentive, and cultural mechanisms. This method can help reconcile institutional logic conflicts caused by multiple logic coexistences in the organizational ecology; (3) A sustainable development model of organizational ecologies for Internet enterprises is presented, based on institutional logic, for closed-loop analysis of the ecological growth path. Based on a case study of China's Internet environment, this paper opens up the "black box" of the internal growth of Internet enterprises at the micro level, complementing the macro studies in the literature. This study enriches organizational ecology theory and institutional logic theory. In addition, the case study of LeEco provides sufficient information on sustainable development to serve as a model for other Internet enterprises.
\end{abstract}

Keywords: organizational ecology; institutional logic; sustainable development; internet enterprises

\section{Introduction}

The development of digital technology has brought unlimited opportunities to businesses that deeply combine Internet and traditional industries. Internet enterprises are born with digital genes across different businesses, trying to break the restraints of industrial chains and to reconstruct the big ecology and big empire of competition patterns [1,2]. For example, Google set up a parent firm called Alphabet to suggest that its business scope is very broad, covering all 26 letters. Apple has perfectly incorporated hardware and software, and redefined cellphones by satisfying its iPhone users with abundant apps. Consequently, smartphones have rapidly overwhelmed other traditional giants, such as Nokia and Motorola. Moreover, this commercial phenomenon is much more commonplace in China with 770 million cyber citizens. For example, Alibaba has created a huge business ecosystem based on e-commerce and the integration of logistics, finance, social life, and entertainment. Likewise, LeEco has developed from a video site to an Internet enterprise with a 150 billion RMB market value, seven ecology organizations and its star, LeSuper TV. However, a common issue for these commercial practices is how Internet enterprises reconcile the conflicts brought by the integration of different industries. To solve this problem, we need to theoretically investigate the conflicts and their origins, and propose resolution mechanisms. 
However, it has been difficult to accurately explain Internet commercial practices using existing management theories. Ever since Moore [3] first proposed the concept of a "business ecosystem", scholars have explored the relationships between a central enterprise and its suppliers, manufactures, distributors, and consumers [4,5]. Most of these explorations view the central enterprise as an integral whole to analyze the interactions with stakeholders; few investigations have focused on the micro perspective of internal organization activities and external environmental change patterns. These defects of business ecosystem theory are redeemed by the theory of organizational ecology. This theory examines how the links among individual organizations affect whole group characteristics, emphasizing the environmental choices of organizations and organizational adaptations to the environment [6]. Thus, the exploration of organizational ecology is able to enrich and improve the management theory in the Internet era.

To date, there have been several defects of theoretical research on organizational ecology. (1) Research focuses on the macro level among different organizational domains, such as the differences in global management between governments and non-governmental organizations $[7,8]$ or comparisons of transformation models of small- and medium-sized enterprises in emerging markets $[9,10]$. We lack detailed explorations in multiple groups within the individual organization at the micro level. (2) Few studies have focused on growth, especially growth paths and mechanisms, instead investigating the birth and death of organizational ecology, such as a study on sports club mortality [11] and the explanation of the enterprise species extinction [12]. (3) New research associated with Internet industries is required; the previous research has mostly been based on traditional industries like wine, fashion design, education, news [13-16], etc.

Accordingly, this study analyzes the reasons and paths for sustainable development of organizational ecology in an Internet enterprise from the perspective of institutional logic. First, the institutional logic theory focuses on the divergent organizational behaviors caused by the long-term coexistence of multiple institutional logics in a multifaceted environment $[17,18]$. This should contribute to analyzing internal organizational ecology conflicts and their causes in Internet enterprises, filling the gaps of research on organizational ecology at the micro level. Secondly, as Dunn and Jones [19] have indicated, the legitimacy of institutional logic and its associations can determine the "game rules" and change assumptions, making it possible to explore approaches to solving conflicts within Internet enterprise organizational ecologies. Last but not least, organizational ecology and institutional theory are complementary, to a certain extent, specifically in their hierarchical correlations [20]. Moreover, the sustainable development of organizational ecology corresponds to a process of obtaining high standards of legitimacy. Therefore, institutional logic theory is appropriate for the research.

This research employs a case study of LeEco, a famous Chinese Internet enterprise with typical ecology characteristics. Since exploratory studies can explain new phenomena with new theories [21], the present work is trying to apply a solution, for an individual Internet enterprise, to the integration of different industries in synergetic development. Accordingly, this article regards LeEco as an organizational ecology, with different industry branches representing different subgroups, so as to raise the issue of exploring integration with different industries, as well as the achievement of organizational and management mechanism. Specifically: (1) What are organizational conflicts that Internet companies have in coordinating the development of different industries? (2) What are the underlying causes of these conflicts? (3) How to resolve these conflicts?

The structure of this paper is as follows: Section 2 studies and reviews the relevant theories and puts forward the research framework of this paper based on the existing research. Section 3 mainly describes the choice of the research method, the data resources and the analysis method. Section 4 is the case description on the background of LeEco, and the key events, decision-making and activities during the development of the organizational ecology. Section 5 is the theoretical analysis on the management phenomena in the case and carries out theoretical explanations, with the statement of the model derivation. Section 6 is the conclusion, which is to summarize the results and give some suggestions on the future study. 


\section{Theory Background and Research Framework}

\subsection{Organizational Ecology and Sustainable Development}

The theory of organizational ecology is an important branch of organizational studies. Base on ecology theory, it combines new institutional economics and industrial economics to study individual development, relationships among organizations, and relations between organizations and the environment [6]. Organizational ecology emphasizes organizational diversity and adaptability within the organizational community or population [22]. Previous studies of organizational community are divided into two levels: organizational ecology and population ecology of organizations. Organizational ecology is concerned with the rates of change in organizations, their natality and mortality, and in explaining relationships between rates of change. Its research methods are based on ecology, rather than on organizational change [23,24]. In contrast, population ecology of organizations mainly studies how the relationships between individual organizations affect the characteristics of the whole group. These studies involve a variety of theories, such as evolutionary economic theory, strategic management theory, institutional theory, and technology and innovation management theories [22]. For example, Liu and Wu [25] studied Chinese law offices, and Manser et al. [26] investigated sustainable innovations of enterprises.

The study of organizational ecology growth begins with the original model of density-dependent theory. Hannan [27] suggested that, during the emergence-growth-stabilization process, relationships between the legitimacy and competitiveness of populations, their establishment rates, and the mortality of an organization appear as an inverted $U$ curve between population density and organizational establishment rate, with a U-shaped relationship between population density and organizational mortality. The density-dependent model, an important part of the theory, was the first to describe the growth path of organizational ecology. Its influence runs through theories of establishment, growth, and death [28]. Scholars have found that the density-dependent model fails to explain the growth path for more complicated organizational ecologies. Therefore, scholars have further expanded the model (see Table 1). Subsequent research is mainly empirical. Cattani and Ferriani [29] analyzed the relationship between the depth of social network links and individual performance in organizational ecology, using U.S. film industry data. Mcevily et al. [30] studied the impact of government and customer on the joint employment relationships of lawyers in the legal industry of Nashville, USA.

Table 1. Six modified hypothesis for density-dependent effect models.

\begin{tabular}{|c|c|c|}
\hline Name & Scholars & Contents and Findings \\
\hline $\begin{array}{l}\text { Mass Dependence } \\
\text { Hypothesis }\end{array}$ & $\begin{array}{l}\text { Barnett and } \\
\text { Amburgey [32] }\end{array}$ & $\begin{array}{l}\text { The intensity of competition in the population is determined by the size } \\
\text { difference of the individuals rather than the population density. } \\
\text { The density-dependent effect tends to weaken at the mature stage } \\
\text { with the increase of the size difference. }\end{array}$ \\
\hline $\begin{array}{l}\text { Competitive Intensity } \\
\text { Hypothesis }\end{array}$ & Barnett [33] & $\begin{array}{l}\text { Considering the interaction between age and size, the competition effect will } \\
\text { be weakened as the age of large individuals (such as oligarchs) increases. }\end{array}$ \\
\hline $\begin{array}{l}\text { Temporal Heterogeneity } \\
\text { Hypothesis }\end{array}$ & Hannan [34] & $\begin{array}{l}\text { The density-dependent effect varies with the age of the population. } \\
\text { For those at the mature stage, the competition intensity depends more on } \\
\text { the individual role in the social structure, while the sensitivity to the } \\
\text { population density decreases. }\end{array}$ \\
\hline $\begin{array}{l}\text { System-Dependent } \\
\text { Selection Hypothesis }\end{array}$ & Lomi et al. [36] & $\begin{array}{l}\text { The environment is commonly considered an endogenous factor in the } \\
\text { evolution of the population. The survival rate of individual depends on the } \\
\text { feedback link between the population and the environment. In other words, } \\
\text { there exists an interaction between the population and its environment. }\end{array}$ \\
\hline
\end{tabular}


Table 1 shows that the six modified hypotheses for density-dependent effect models have enhanced the explanation of sustainable development path for organizational ecology. However, current studies are still based on the macro perspective of different industry groups, lacking micro-detailed research on different groups within the same organization.

\subsection{Institutional Logic}

Institutional logic refers to the social level of culture, beliefs, and regulations by which individuals and organizations think and behave. Logic is the assumptions and values for social sharing. It can form a fixed cognitive framework and be a standard for measuring legitimacy $[18,19,37,38]$. Institutional logic focuses on the phenomenon of organizational differences resulting from multiple coexisting institutional logics in a pluralistic institutional environment and emphasizing organizational reconstruction [17]. The early research on institutional logic focused on a single "dominant logic" and its changes on the industrial level and organizational field [39,40]. A representative study by Thornton and his team investigated the transformation process of U.S. higher education publishing from "editorial logic" to "market logic" [18,41,42]. Previous research established foundations for institutional logic and brought about subsequent discussions. Scholars turned to the multiple requirements and complexity of the internal interactions of pluralistic institutional logics [43,44]. For example, Cobb et al. [45] studied the important role of business organizations and public investor funding for small loans. Ocasio and Radoynovska [46] revealed the significance of organizational heterogeneity to the creation and acquisition of corporate value. Zhu et al. [47] analyzed the complicated relations between social and business logics of the enterprises, constructing a theoretical model which can be compatible for both.

Legitimacy is a core concept for institutional theory, closely related to the theory of institutional logic [48]. Scott [49] argued that institutional logic is inclined to a macro conception; therefore, a lack of rapid institutional changes and developments is usually seen as a prerequisite or circumstance affecting an enterprise. However, legitimacy is the perception result of a micro individual in social evaluations. It directly acts on humans and has a more direct impact on enterprises. Accordingly, the definition of legitimacy given by Suchman [50] has generally been recognized by academia: Legitimacy refers to the behavior of an entity in a particular social system conforming to social norms, values and beliefs, perceived or regarded as appropriate. Legitimacy is essential to organizational development. Organizations can acquire or enforce legitimacy by using strategies in activities [51]. Consequently, numerous researchers have studied enterprise legitimacy from the institutional perspective, emphasizing institutional impact on enterprises. It is believed that the acquisition of legitimacy is a response to the pressure of institutional environments [52-54]. Moreover, Bruton et al. [55] believed that enterprise legitimacy consists of relational and institutional strategies, and confirmed the importance of the institutional establishment in legitimacy. Spilker and Koubi [56] showed that the impact is extensive in the evolution of multiple institutions which offer people the chances to adapt, select, manipulate, and create new institutions, although with the purpose of legitimacy. Therefore, the effect of institutional logic depends on organizational legitimacy.

\subsection{Research Framework}

Few scholars have studied the sustainable development of organizational ecology from the perspective of institutional logic and legitimacy. The existing research has mostly focused on the analysis of ecology growing paths and their impacts, lacking an investigation of the "black box" of sustainable development mechanisms. Institutional logic is a complement. In addition, the Chinese Internet industry is missing in studies of sustainable development of organizational ecology. Thus, based on the Chinese Internet industry, this article discusses the interactions and effect mechanisms of organizational ecology of institutional logic and legitimacy construction, which is "WHW" (see Figure 1). The first "W" indicates "Which": Which institutional logic exists in organizational ecology of the Internet companies? The " $\mathrm{H}$ " stands for "How": How to coordinate 
multi-institutional logic in organizational ecology and construct legitimacy? The last "W" means "What": What are the legitimacy foundations that affects the sustainable development of organizational ecology in the Internet companies?

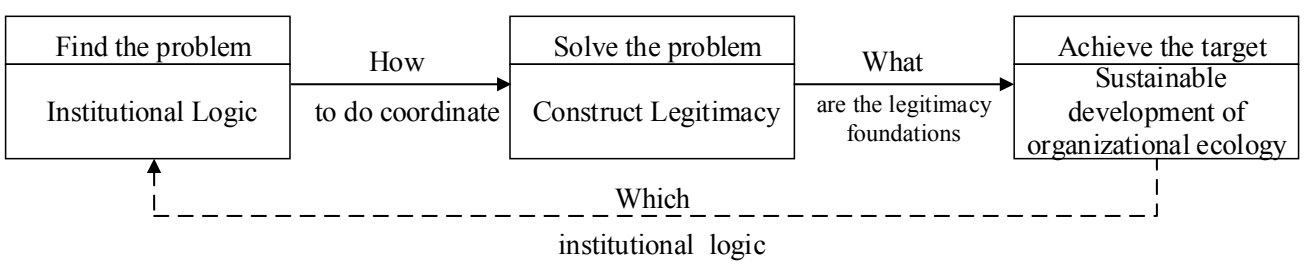

Figure 1. Research framework.

\section{Research Method and Data Resources}

The reasons for the exploratory single case study of this article are as follows. Firstly, the target of this study is to answer "how" to achieve sustainable development, focusing on the process of doing it. Meanwhile, we present a dynamic process from the process perspective. Therefore, it is appropriate to adopt case study method [21]. Secondly, this paper is trying to explain a new phenomenon of the Internet enterprises in China. However, there is a lack of in-depth analysis of such phenomenon. Hence, we need to adopt the exploratory study method in the case of limited knowledge in the field of research [57]. Finally, since our research is systematic and deeply exploratory, a single case for analysis is required for its massive data [21].

This article chooses LeEco as the research object for three reasons. First, as an Internet enterprise, LeEco covers such businesses as Internet video, film production and release, and intelligent terminals. With the most prominent ecological features and best potential among Chinese Internet enterprises, LeEco is obviously an enterprise driven by ecological strategies. Its market value is about 20 times higher than traditional enterprises of the same size, thus meeting the principles of being important and representative [58]. Second, in adhering to ecological strategies, LeEco owns seven sub-ecologies distinctively different from the ecosystems established through capital acquisitions. Therefore, this case was chosen out of theoretical needs, such as proposing new theories or improving existing theories, rather than merely being part of a larger sample [59]. The selection of the study sample complies with the principle of theoretical sampling. Third, interesting phenomena have appeared in the development of LeEco organizational ecology. Moreover, LeEco has undergone constant organizational reconstructions, which provides a great deal of study data, thus serving our theoretical aim and research objective.

The data for this study was collected via multiple methods, including enterprise investigation, in-depth interviews, internal and external materials, and the recycled strategy [60]. The data sources mainly come from three aspects. First, the writer conducted a field investigation on LeEco on 24-26 March 2016 and 26-28 July 2016 and conducted in-depth interviews with 27 middle-management and senior personnel and technical principals in the strategy, human resources, product, operations, finance, and information departments. The author kept interview records of 100,000 words. Each recorded interview lasted from 90 min to two hours. Moreover, LeEco employees studied for MBAs in the author's unit and the author had the opportunity to guide their theses and learn from their experiences in the organizational ecology growth of LeEco. Some of the employees have worked for the company for many years and participated directly in the construction and management of its organizational ecology, providing valuable materials for the author. Last but not least, the author collected information through the Internet, published theses, and books. The study performed triangle verification according to these different sources and interviewers, selecting reliable data [57]. 


\section{Case Description}

LeEco was founded in 2004, and its initial business was video websites, with the core competence in contents. The success of LeEco makes it foresee the prospects of the content industry. After LeTV (a branch of LeEco, with business in the production of super TVs) was listed on the GEM A-share market in 2010, the company continued to seek cross-border integration and development. It combined the content advantages with other industries. In 2012, the company launched its LeSuper TV and Super Electric Ecosystem (SEE) plan in 2014. In 2015, LeMobile, LeMusic, and a terminal intelligence company came out one after another. Meanwhile, the LeEco merged YongcheInc, had stakes in TCL and Coolpad, and continued layout in super TV, mobile phones and automotive sectors. Additionally, LeEco ecosystem includes contents, large screens, mobile phones, automobiles, sports, Internet cloud and Internet finance. Virtual products are called content ecology and others terminal ecology. Figure 2 shows the development path of LeEco.

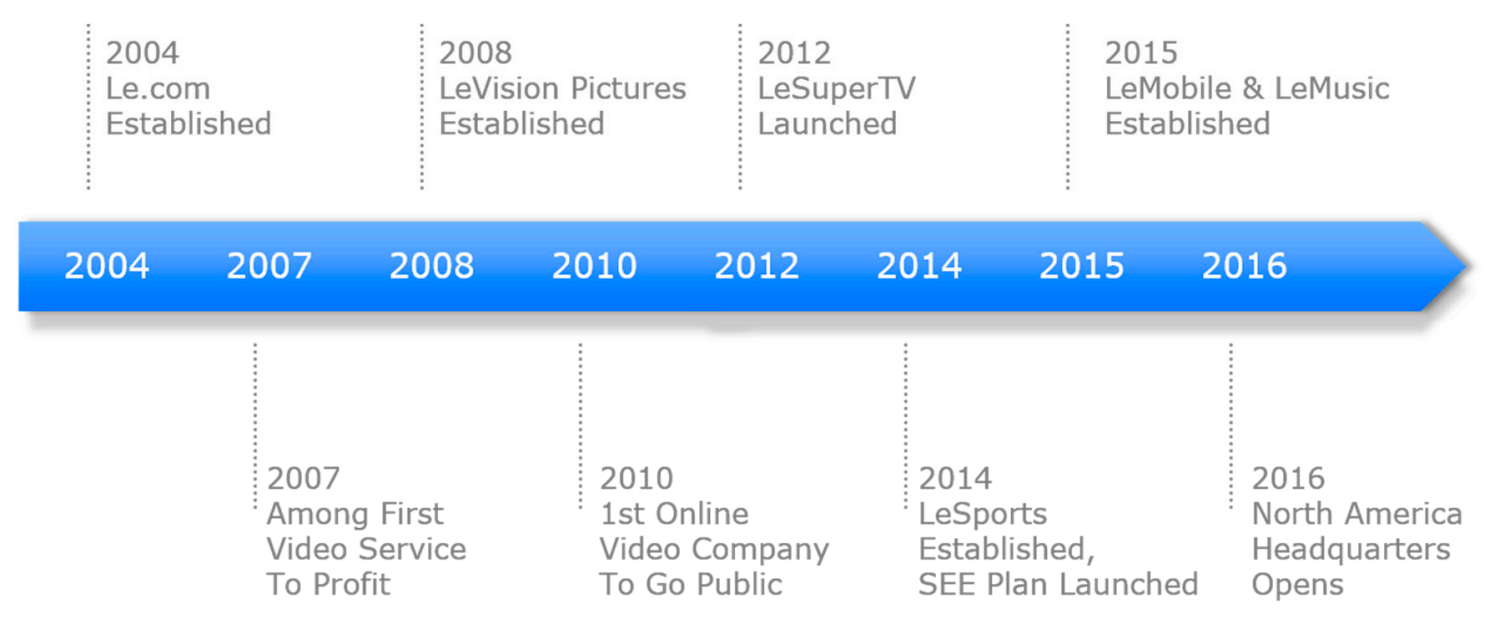

Figure 2. Development path of LeEco.

In this section, we describe the content ecology, the terminal ecology and the integration of the content and the terminal ecology of LeEco. In the content ecology part, we mainly introduce the copyright acquisitions and the Homemade+Mergers and Acquisitions. In terms of the terminal ecology, we mainly introduce the terminal products and the profit model. In the integration of the two kinds of ecology, we show the cooperation and conflicts during the process by the example of LeSuper TV development.

\subsection{Content Ecology: Providing Users with Abundant Contents}

One of the major features of the Internet industry is massive digital resources, such as data, information, video contents, etc. Founded as an Internet video website, the most important way for LeEco to attract users is to provide high-quality contents, which is also its core asset. At present, the LeEco content industry includes movies, dramas, animations, sports, etc. It has more than 100,000 episodes of dramas and over 5000 movies, with popular TV plays accounting for $70 \%$ of the total market. The total valuation of contents is above 10 billion RMB. This paper summarizes two steps as follows.

\subsubsection{Copyright Acquisitions}

LeEco was founded in 2004. China's copyright market was very chaotic at that time, with rampant piracy and no copyright awareness. However, LeEco saw a broad space for the content industry. Therefore, LeEco bought numerous high-quality copyrights in movies and dramas when market prices were very low. 
Current market prices for copyright material are very high, making the massive copyrights LeEco has bought very competitive. For example, LeEco invested in The Legend of Miyue in 2015. The price for the 80-episode drama has increased to over five million RMB per episode.

\subsubsection{Homemade Content, Mergers, and Acquisitions}

In order to attract users, LeEco has produced homemade content and merged creative teams of movies and dramas.

In the homemade field, LeEco mainly depends on its own homemade team and Le Vision Entertainment. The in-house team can produce films, dramas and TV shows. A typical example is the on-line drama Go Princess Go. Le Vision Entertainment was founded in 2011, focusing on producing and publishing movie content. The contracted directors include Zhang Yimou, Lu Chuan, Zhang Xiaolong, Tsui Hark, Gao Xiaosong, Guo Jingming, etc., with published movies like The Great Wall, Time Raiders, Legend of Ravaging Dynasties, Coming Home, the Tiny Times series, Boonie Bears, etc.

In the mergers and acquisitions (M\&A) field, LeEco enriches its content industry through acquisitions of outstanding video production teams. For example, LeEco purchased Flower Film and TV in 2012 for its creativity in films and dramas. After the acquisition, The Legend of Miyue was widely recognized and praised.

\subsection{Terminal Ecology: Providing Users with a Good Experience}

The main terminal businesses of LeEco include TV, cellphones, and automobile businesses, which correspond to the ecosystem circles of large screen ecology, cellphone ecology and automotive ecology, respectively. The company's automobile terminal plan was launched in 2014 and is still under construction. Among all its terminal businesses, the most successful one is LeTV. Founded in 2009, LeTV has been focusing on set-top boxes and intelligent televisions. Additionally, LeEco has replicated its big screen success into intelligent cellphones. This article reviews two key LeEco points of access to developing terminal businesses.

\subsubsection{Terminal Products with Contents}

Both TVs and cellphones are of traditional markets. To set foot in these traditional industries and tip the balance, an Internet company must be outstanding. The advantage of an Internet company is having a large number of digital resources. LeEco combines its content advantage with terminal equipment to develop competitive terminal products. Due to its unique content resources, its competitiveness is also inimitable.

Aside from contents, users are also concerned about hardware performance, which LeEco takes seriously. As is known to all, the overall performance of terminal products includes hardware and software. Take LeSuper TV as an example. In software, LeEco independently developed an EUI system based on the intelligent terminal of LeTV. The system integrated all the available resources of LeEco with a simple user interface and a highly fluent system, especially highly integrated LeEco applications which offer user convenience. In terms of hardware, LeTV supplied $1.4 \mathrm{GHz}$ quad-core CPU, $3 \mathrm{~GB}$ large memory, 16 GB high-speed flash memory, dual-band WiFi, Bluetooth 4.0, USB 3.0, HDMI 2.0 and Dolby and DTS sound. Furthermore, LeEco cooperated with Qualcomm and Mstar to develop the chips needed for super TVs.

\subsubsection{Negative Zero Pricing Profit Model}

While LeEco pursues good experience for its users on its terminal products, cost is also considered. How does LeEco solve these contradictions?

Take LeSuper TV as an example. There were three major drawbacks in the early smart TV market: price, simplistic marketing, and a simplistic profit model. Considering its contents strength, LeEco adopted a negative zero pricing profit model. Accordingly, compared to traditional TV manufactures, LeSuper TV has three profit points: membership fee income, advertising revenue, and game 
distribution income. In 2013, while the market price for a smart TV generally exceeded 10 thousand RMB, the 60-inch LeSuper TV was a competitive 6000 RMB. Therefore, LeEco has profited through fascinating terminal products and service fees from ecological contents.

\subsection{Contents and Terminal Integration: LeSuper TV}

We can conclude from LeEco's development that content resources help LeEco make profits, and terminal products give users better experience and in turn bring more users, which contributes to the company ecosystem. However, the contents and the terminals belong to two completely different industries. Their integration is a great challenge for technology and management, in four aspects especially: communication, practice, incentive and culture. Firstly, people in different industries have different knowledge structures. How can they understand the "language" of the other? Secondly, even though the target is identical, they have different demands for working resources in practice, not to mention the conflicts brought by the allocation of work resources. How do they solve the contradictions and cooperate effectively? Thirdly, it is difficult to measure the contribution of different industries. Efficient and fair motivation of employees thus becomes a difficult issue. Lastly, there are cultural cognition differences between different industries. How to make people work in harmony? As explained previously, the strength of LeSuper TV is its integration of content with terminal. Therefore, this article will analyze the strategy LeEco adopts to integrate and develop these two different industries.

\subsubsection{Conferences}

LeEco has solved the communication issues with conferences brought by contents and terminals. There are three kinds of meetings:

The "president meeting", each Monday morning, is the highest level of decision-making conference, with 150 attendances. Executives from each department are required to attend. The meeting is generally from 9:00 a.m. to 3:00 p.m. Themes revolve around strategic decisions and, most importantly, the possibility of combination and innovation between different industries ("anti-point"). For example, LeEco is considering producing TVs. How to distinguish itself from the other companies in the market? As mentioned above, the strength for LeEco is content resources. Hence, the idea of combining contents with TVs is discussed in the president meeting. According to Hu Jinsong, a vice president of human resources department in LeEco, "The president meeting has over 100 attendances. Why are so many people required to attend? It is mostly because that the meeting brings different ecologies together to spark inspirations and learn from others as long as you are willing to."

The second type of meeting is the "eco-collaboration meeting" each Sunday afternoon. The management of LeEco has a six-day workweek (regular staff have a five-day workweek). In the "eco-collaboration meeting" for each ecology, innovations from the president meeting are conveyed to relevant business units to implement the key nodes in the collaboration. For example, on the collaboration meeting of LeSuper TV, leaders of all business units associated with super TV-contents, user operations, EUI systems, and supply chains-will attend to discuss issues about collaborations: how to design the contents for user focus, how to upgrade the EUI system, how to purchase external screens to meet the content resolution requirements. Plans on resource supports are carried out after the discussion, for quick execution.

The third type is regular departmental meetings of each ecosystem on weekdays. For example, super TV business will lead project implementation after getting support from the eco-collaboration meeting on Sunday. The problems during the implementation will be discussed and solved on regular departmental meetings.

LeEco solves the problem of knowledge structure differences between different industries via meetings. "There is a particularly good idea, that is, people are completely irrelevant. Meetings make them understand. Such kind of experts do not exist in professions. They are trained only in the LeEco 
system for a certain period of development and accumulation", According to Yu Chao, an operation director of the content operation center in LeEco.

\subsubsection{Project Management Organizations}

In LeEco, CEO Jie Yueting says that "Strategy decides organization, and organization decides success". Its cross-industry development strategy means LeEco organizes project management after decision making. In project management organizations, enterprise organizational structure consists of departments with management functions (such as strategy, human resources, finance, user operation, etc.) and project teams which are specially organized for a certain product or activity.

For example, LeEco recently launched a project called "video interconnection", synchronizing cinema movies to broadcast a large number of excellent films to the audience. This project is typically multi-industry, involving the super TV, Le Vision Entertainment, and the EUI research and development (R\&D) center. Due to copyright issues, EUI R\&D uses encryption chips to allow those who have paid to watch the movies.

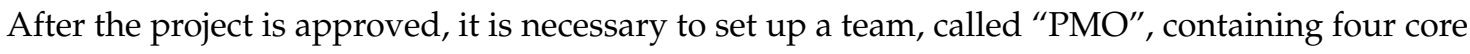
roles: (1) PO (project order), held by the president of the super TV department, who is responsible for the overall leadership of the project; (2) PM (project manager), responsible for operation; (3) Strategy BP (business partner), assigned by the management strategy department, responsible for resource support and project promotion; (4) Financial BP, assigned by the finance department, responsible for management. Afterwards, a number of sub-projects are set according to specific business lines. For example, a sub-project is set to contact the film bureau in the "video interconnection" project, and a team is set to contact Mstar Corp. to develop encryption chips. It is worth mentioning that the core personnel of the teams are usually directors, such as the first-line traders and backbones. During a project, they can rapidly improve their multi-industry management capabilities. Communications between project teams can be both formal and informal. The formal ones are in the weekly eco-collaboration and regular meetings, while the informal ones meet through WeChat groups. For example, the "video interconnection" project has a 200-person WeChat group with all its members. All the general problems can be discussed directly in the group, so that executives in the group can make quick decisions. "Unlike other companies, LeEco relies deeply on project management organizations. We may have hundreds of projects simultaneously, most of which are usually cross-ecology. It is hard to depend on traditional organization boundaries. Therefore, we can break the boundary by project organizations", says Chen Shijiang, a LeEco Strategy Director.

\subsubsection{Incentive Allocation Mechanism}

The characteristic of a project management organization is multi-dimensional management, for which the most difficult problem is performance evaluation. It may decrease the enthusiasm for work and increase the messes at work. Therefore, it is important to motivate members in project management organizations. LeEco implements a "highest cross-shareholding" incentive mechanism.

For instance, in the "video interconnection" project, those in charge of super TV belong to Le EUI, while those in charge of film contents belong to LeVision Pictures. Both belong to LeEco. Therefore, both LeSuper TV and film-making personnel can choose to hold either Le EUI or LeVision Pictures shares. As long as the project is a success and makes profits, the employees of both departments can be motivated. "This incentive mechanism can ensure both synergy of the whole project and the focus on a single business. The strategic target is to realize the development of each sub-ecology as well as the whole synergy, maximizing the overall benefits", according to HU Jinsong, a vice president of a human resources department in LeEco.

\subsubsection{Lion-And-Wolf Culture}

LeEco has carried out a series of institutional constructions in communication, implementation, and incentives. The purpose of these is the collaboration of different industries and the growth of 
LeEco organizational ecology. LeEco has developed a lion-and-wolf culture, in contrast to the traditional saying that "two tigers cannot live on the same mountain". This culture advocates that it is possible for the talents of different industry backgrounds, thinking modes, or strategic patterns to work together and mutually benefit. According to Chen Shijiang, a LeEco Strategy Director, "In fact, there were some struggles between companies. We had foreseen them and proposed "lion-and-wolf culture" in the hope of solving the problems with a broader attitude."

\section{Discussion}

In this part, we study the case from three aspects as follows. Firstly, on the ground of the case description above, we identify institutional logic in organizational ecology of LeEco. Secondly, through the analysis of institutional logic, we find out the conflicts and barriers in the sustainable development of its organizational ecology. Last but not least, we discuss how LeEco resolved conflicts by institutional practices, and how legitimacy is constructed and sustainable development of organizational ecology is realized.

\subsection{Cultural and Manufacturing Logics: Leading Institutional Logics of LeEco in Organizational Ecology}

The impact of organizational ecology is manifested in three aspects: human, activity, and atmosphere [6]. LeEco has two industries, content and terminal; thus, we identify the institutional logic in LeEco's organizational ecology by analyzing the differences in human beings, activity, and atmosphere between the two industries (see Table 2). Most employees of the content industry are relatively artistic, with work experience and academic background in the creation of films and TV shows. Comparatively, employees of the terminal industry are known for their knowledge of computer science and engineering, and are more suitable for technical work. The content industry deals with artistic creations, providing abundant content for the audience, while the terminal industry deals with engineering, to turn ideas into products. Finally, due to the differences in job categories, the work atmosphere for the content industry is relatively comfortable and active, compared with that of the terminal industry, which tends to be severe and intense, to ensure product quality. Consequently, the content industry focuses on the spiritual culture level, which is defined as cultural logic; the terminal industry focuses on the manufacturing level, which is defined as manufacturing logic.

Table 2. Institutional logic of LeEco in organizational ecology.

\begin{tabular}{ccc}
\hline Organizational Ecology & Content Industry & Terminal Industry \\
\hline Human Being & Artistic preference & Technical preference \\
Activity & Inspiration creation & Project realization \\
Atmosphere & Comfortable and active & Sever and intense \\
Institutional Logic & Cultural logic & Manufacturing logic \\
\hline
\end{tabular}

The organizational ecology of LeEco contains both cultural and manufacturing logics. What are the differences between the two kinds of logic? Researches have shown that multi-institutional logic mainly affects organizational behaviors and strategy choices [61]. In contrast, strategy choices and organizational behaviors are essential for the formation of enterprise organizational ecology [22]. Therefore, this article examines the dimensions of strategy choices and organizational control to compare cultural logic and manufacturing logic in the organizational ecology of LeEco.

Strategy choices refer to changes in the business decision-making processes with respect to the market environment, targeting enterprise development [62]. The content and terminal industries of LeEco's organizational ecology have entirely different strategy choices under different institutional logics (see Table 3). In the early days, copyright consciousness was weak. The LeEco content industry bought a large number of film and drama copyrights at low cost to gain market share. After the price of copyright began to increase in the heat of market competition, LeEco acquired other film companies, drawing on its own accumulative advantages. In addition, it organized some teams 
to create homemade dramas to support users with more and better content resources than before. Subsequently, LeEco adopted an expansion strategy in the content industry to keep expanding and strengthening its existing advantages in content resources. Meanwhile, it chose a centralized strategy in the terminal industry, developing terminal products matching its content resources. LeEco chose a pricing strategy of free hardware, charging for content.

Table 3. Strategic choice of cultural logic and manufacturing logic.

\begin{tabular}{cll}
\hline Institutional Logic & Strategy Choice & \multicolumn{1}{c}{ Data Support } \\
\hline Cultural Logic & Expansion Strategy & $\begin{array}{l}\text { LeEco continues to innovate and update to support } \\
\text { users with good and exciting content resources. }\end{array}$ \\
\hline Manufacturing Logic & Centralized Strategy & $\begin{array}{l}\text { Our intelligent terminal is relevant to the content. } \\
\text { The ultimate target is to improve the viewing } \\
\text { experience of users. }\end{array}$ \\
\hline
\end{tabular}

Organizational control refers to the management styles adopted to make individual behaviors conform to organizational targets [63]. In general, an enterprise adopts more than one management style [63]. In LeEco's organizational ecology, the content industry, with its cultural logic, adopts a combination of cultural control and self-control, namely informal control. The terminal industry, using manufacturing logic, adopts a combination of outcome control and behavior control, namely formal control [64] (see Table 4). Cultural control assumes that the organization members have the same standards and values, so that rewards and punishments depend on whether the individuals meet these criteria and values [65]. LeEco merged numerous film companies in the content industry and managed them in the ecology of "Le Ecosystem". Self-control means that the organization is able to guide its members to develop their own targets with a certain mechanism, along with self-supervision, self-motivation, and self-punishment in practice [66]. Content creation needs space and freedom. Thus, the management style for content creation members is tactical, using flexible schedules and open offices and layouts. Outcome control indicates that the organizational reward depends on whether a certain goal is achieved, regardless of the process [66].

In the terminal industry of LeEco, each terminal device is developed for a specific purpose. The performance of researchers is anchored to the completion of a working schedule. There are always rewards for conquering each technical barrier. This behavioral control relies on a bonus-penalty system based on obedience to appropriate behaviors set in advance [67]. Compared to the members of the content industry, staff in the terminal industry are supervised more strictly, for instance with clock-on discipline and a tense atmosphere at work (see Table 4).

Table 4. Cultural logic and manufacturing logic in organizational control.

\begin{tabular}{|c|c|c|c|}
\hline Institutional Logic & Combinatic & is of Control & Data Support \\
\hline \multirow[b]{2}{*}{ Cultural Logic } & \multirow[b]{2}{*}{ Informal Control } & Cultural Control & $\begin{array}{l}\text { The contents are wide-ranging, under the core } \\
\text { value of Le ecosystem management though. }\end{array}$ \\
\hline & & Self-Control & $\begin{array}{l}\text { Considering the creative demand of staff in the } \\
\text { cultural industry, the management is } \\
\text { unrestrained. }\end{array}$ \\
\hline \multirow[b]{2}{*}{ Manufacturing Logic } & \multirow[b]{2}{*}{ Formal Control } & Outcome Control & $\begin{array}{l}\text { For each product model, we draw up detailed } \\
\text { technical index and time schedules. }\end{array}$ \\
\hline & & Behavior Control & $\begin{array}{l}\text { We have very strict routine system, which } \\
\text { must be strictly obeyed by both executives } \\
\text { and staff. }\end{array}$ \\
\hline
\end{tabular}


5.2. Resource Barriers and Information Barriers Are the Expressions of Multi-Institutional Logic Conflicts in LeEco Organizational Ecology

Thornton [61] has pointed out that institutional and individual behaviors are jointly shaped by the conflicts and compatibility of institutional logic. Cultural logic and manufacturing logic coexist in the organizational ecology of LeEco. Conflicts between the two logics are unavoidable, specifically presented as product assortment conflicts and organizational conflicts (see Table 5).

Table 5. Two conflicts caused by the poly-institutional logic of LeEco organizational ecology.

\begin{tabular}{|c|c|c|c|}
\hline & Cultural Logic & & $\begin{array}{c}\text { Manufacturing } \\
\text { Logic }\end{array}$ \\
\hline Strategy Choice & $\begin{array}{l}\text { Expansion } \\
\text { Strategy }\end{array}$ & $\begin{array}{l}\text { Product } \\
\text { Assortment } \\
\text { Conflicts }\end{array}$ & $\begin{array}{l}\text { Centralized } \\
\text { Strategy }\end{array}$ \\
\hline $\begin{array}{c}\text { Organizational } \\
\text { Control }\end{array}$ & $\begin{array}{l}\text { Informal } \\
\text { Control }\end{array}$ & $\begin{array}{l}\text { Organizational } \\
\text { Conflicts }\end{array}$ & Formal Control \\
\hline
\end{tabular}

Product assortment is the process of optimizing the combination of production factors and resources owned by or available to an enterprise [68]. In the organizational ecology of LeEco, the content industry has used an expansion strategy to build a relatively complete product system in fields such as movies, dramas, network-made dramas, and sports games. However, since the terminal industry has chosen a centralized strategy to integrate content into new hardware devices, there will be some conflicts during the new product development process. Further research shows that the product assortment conflicts in LeEco's organizational ecology are expressed in resource barriers and information barriers (see Table 6). The resource barriers mainly refer to disagreements of work resource distribution. For example, in the "video interconnection" project, staff from both the content and the terminal industries are collaborating on new product development. Funding is confirmed, but it is hard to determine specific expenditure proportions on contents and terminals. Therefore, there is always disagreement on project expenditures. Resource distribution happens not only in financial resources, but also in human resources and materials. Moreover, information barriers are also a typical expression of product assortment conflicts. Information barriers refers to the communication problems caused by knowledge-structure differences between the staff from the content industry and from the terminal industry. For instance, in the video interconnection project, staff from both the content and the terminal industries should work together for the final products. However, there remain a number of information barriers in this process due to differences of knowledge structure.

Table 6. Institutional logic conflict of LeEco organizational ecology: product combination conflicts.

\begin{tabular}{ll}
\hline \multicolumn{1}{c}{ Manifestation } & \multicolumn{1}{c}{ Data Support } \\
\hline $\begin{array}{l}\text { Resource Barriers: disagreements of work } \\
\text { resources distribution }\end{array}$ & $\begin{array}{l}\text { The most direct conflict of a cross-industry team in } \\
\text { LeEco is the distribution of people, money and } \\
\text { materials. }\end{array}$ \\
\hline $\begin{array}{l}\text { Information Barriers: differences of } \\
\text { knowledge structure }\end{array}$ & $\begin{array}{l}\text { The biggest obstacle of cross-industry cooperation is to } \\
\text { understand the professional language of the other. }\end{array}$ \\
\hline
\end{tabular}

Organizational coordination indicates the combination of scattered elements in the organization to achieve synergy and the same target [69]. In LeEco's organizational ecology, the cultural-logic-oriented content industry relies on informal control (cultural control and self-control), while the manufacturing-logic-oriented terminal industry relies on formal control (outcome control and behavior control). Where there are two kinds of members with different management controls working in one organization, such as on the video interconnection project, there are organizational coordination conflicts. This paper has found that, as with product combination conflicts, the organizational 
coordination conflicts in LeEco's organizational ecology are also manifested in resource barriers and information barriers (see Table 7). Specifically, resource barriers refer to divergence in performance rewards distribution. LeEco relies on cultural control for the staff of the content industry, which means the performance rewards depend on whether the works accord with the ecological values of the company. Yet it also relies on outcome control for the staff of the terminal industry, which means performance rewards depend on whether a predetermined target is achieved. Therefore, if the product of collaboration is a success, there will be a divergence in performance rewards distribution: who contributes more, and who deserve more? If the problem remains unsolved, the enthusiasm of members and organizational ecology growth will be affected. In addition, information barriers are differences in cultural style from the two industries. The content industry adopts self-control, with casual working forms and open minds, while the terminal industry adopts behavior control, with formal work environments and rigorous thoughts. If two entirely different types of staff work in the same group, how can the contradictions caused by culture differences be reduced? How can the staff appreciate each other?

Table 7. Institutional logic conflict of LeEco organizational ecology: organizational coordination conflicts.

\begin{tabular}{ll}
\hline \multicolumn{1}{c}{ Manifestation } & \multicolumn{1}{c}{ Data Support } \\
\hline $\begin{array}{l}\text { Resource Barriers: divergence in performance } \\
\text { rewards distribution }\end{array}$ & $\begin{array}{l}\text { Previously in LeEco team, benefit distributions often } \\
\text { cause disputes and contradictions. }\end{array}$ \\
\hline Information Barriers: differences in cultural style & $\begin{array}{l}\text { Employees are respected in their own professions } \\
\text { with their own culture; nobody would give in. }\end{array}$ \\
\hline
\end{tabular}

This paper identifies the two institutional logics in the organizational ecology of LeEco, analyzing the differences between them. It is concluded that the conflicts in the multi-institutional logic are mainly embodied in resource barriers and information barriers. Therefore, how to break these barriers has become the key factor for the institutional ecology growth of LeEco. Previous studies have shown that the process of breaking organizational barriers is essentially the process of obtaining legitimacy, or the response to the institutional environment pressure [52]. Consequently, facing the multi-institutional conflicts in organizational ecology, obtaining product, and organizational legitimacy is the way to break barriers and promote the sustainable development of organizational ecology.

\subsection{Effective Institutional Practice Is Able to Resolve Conflicts in Institutional Logic and Construct Legitimacy to Create Sustainable Development of the Organizational Ecology}

Institutional logic indicates that among the multi-institutional logics, there are not only competition and conflict, but also integration and compatibility [70]. Therefore, new mechanisms must be created to resolve conflict and achieve compatibility of the multi-institutional logics in the organization. Institutional practice refers to the activities of behavioral agents, including preservation, unblocking, and innovation of the institution under a certain institutional arrangement [71]. Due to efficient institutional practices, conflicting institutional logics become compatible and obtain organizational legitimacy, resulting in sustainable development of the organizational ecology. LeEco's organizational ecology adopts some innovative mechanisms in institutional practices, such as implementation, conferences, performance, and cultural mechanisms. These mechanisms have overcome the barriers caused by the conflicts of the cultural logic and the manufacturing logic.

\subsubsection{Legitimacy Construction of "Content + Terminal" Products}

Product combination conflicts are mainly reflected in resource and the information barriers, indicating specifically the communicative problems caused by disagreements of work resource distribution and differences of knowledge structures (see Figure 3). In this regard, LeEco implements "project management" organizations: within the project group, the strategy BP and the financial BP jointly operate the project, while the project order coordinates resources and the project manager is 
responsible for the operation. As in LeEco's "video interconnection" project, the strategy BP stands for the interests of the group, coordinating required human and material resources from both the content industry and the terminal industry. The financial BP allocates the funds of both sides according to the facts. In this situation, the project manager can devote him- or herself to the analysis of user demands and the development of products, without the worries of the group about the distributions of working resources. Therefore, LeEco adopts project management organizations as implementation mechanisms in product development, changing the resource barriers caused by institutional logic conflicts into resource synergy.

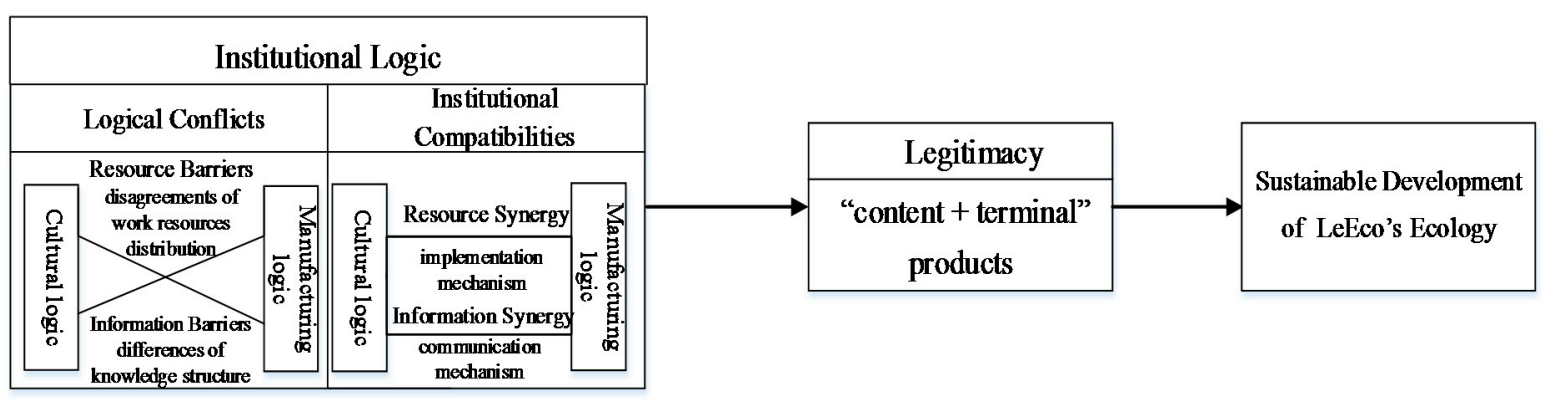

Figure 3. Product legitimacy construction of LeEco organization ecology.

In terms of different knowledge structures, the distinctive meeting system breaks through communicative barriers (see Figure 3). In the president meeting, staff of different industries and professional backgrounds discuss issues to create new ideas on products. The "eco-collaboration meeting" aims at implementing the strategy from the president meeting and analyzing potential problems and solutions from feasible perspectives. At this type of meeting, staff with different knowledge structures communicate with each other, lifting the barriers caused by structural knowledge differences. Regular department meetings deal with specific details at work. The three-level meeting system of LeEco provides staff from different knowledge structures with communication opportunities, which basically removes the information barriers.

Regarding the product combination conflicts caused by cultural logic and manufacturing logic, LeEco adopts project management organizations as the implementation mechanism to break the resource barriers, and uses the multi-level meeting as the communication mechanism to break information barriers, finally obtaining product legitimacy, namely the "content + terminal" products (see Figure 3). Both LeSuper TVs and Super Mobiles are typical "content + terminal" products, which are recognized by consumers in the market and promote the growth of LeEco's organizational ecology.

Figure 3 shows the product legitimacy construction of LeEco organization ecology. Regarding the resource and information barriers in product combination conflicts, LeEco adopts project management organizations as implementation mechanism and meeting system as communication mechanism to achieve resource synergy and information synergy, finally obtaining product legitimacy and promoting the growth of LeEco's organizational ecology.

\subsubsection{Legitimacy Construction of Ecological Organizations}

The organizational coordination conflicts of LeEco's organizational ecology are also demonstrated in resource barriers and the information barriers. However, in contrast to product assortment conflicts, resource barriers refer to divergence in performance rewards distribution, while information barriers refer to differences in cultural style (see Figure 4). On account of the divergence in performance reward distribution, LeEco implements the highest cross-shareholding incentive mechanism, in which the staff of either the content industry or the terminal industry take shares of both LeEco holding and the subsidiary companies. As long as the project is successful in the market, the employees of both sides can choose a relatively high equity as the ultimate stakeholder based on the equity value. In this way, 
the problem of the divergence in performance reward distribution is solved effectively. Staff from both sides no longer worry about unfair rewards when they are cooperating on product development.

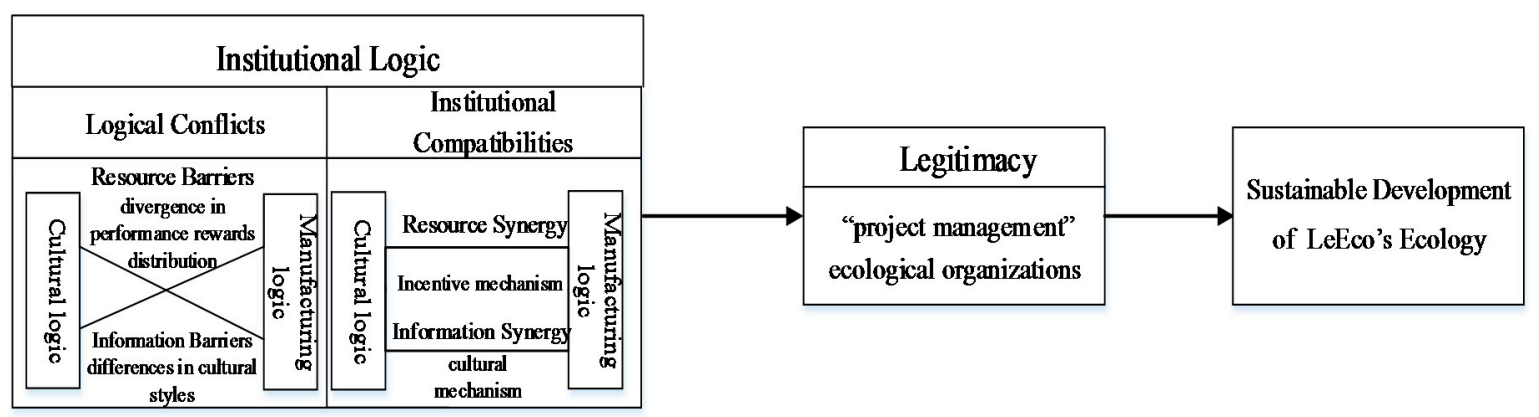

Figure 4. Organizational legitimacy construction of LeEco.

In consideration of the differences in cultural styles, LeEco implements the lion-and-wolf culture (see Figure 4). Due to the needs of product development, the staff from different industries often work together in a project team. They obey different institutional logics, having different work habits and life styles. The essence of lion-and-wolf culture is to emphasize the inclusion of different styles, recognition of the values, and cooperation on the basis of respect for other styles. Therefore, the lion-and-wolf culture of LeEco has played an important role in the integration of cultural and manufacturing logic.

Figure 4 shows the organizational legitimacy construction of LeEco. Regarding the resource and information barriers in organizational coordination conflicts, LeEco implements the highest cross-shareholding incentive mechanism and the lion-and-wolf cultural mechanism to achieve resource synergy and information synergy, finally obtaining legitimacy of the organization's ecology and promoting the sustainable development of LeEco's ecology.

LeEco implements the incentive mechanism of highest cross-shareholding and the cultural mechanism of lion-and-wolf culture. These mechanisms effectively resolve the coordination conflicts of institutional logic, changing resource barriers and information barriers into resource synergy and information synergy, and obtaining legitimacy of the organization's ecology (see Table 8).

Table 8. Construction of legitimacy and growth of organizational ecology.

\begin{tabular}{cll}
\hline Legitimacy Construction & Results & \multicolumn{1}{c}{ Data Support } \\
\hline Product Legitimacy & Ecology Growth & $\begin{array}{l}\text { The success of such products as } \\
\text { LeSuperTV in the market brings generous } \\
\text { profits and capital injections. }\end{array}$ \\
\hline Organization Legitimacy & Ecology Growth & $\begin{array}{l}\text { LeEco explores a set of organization and } \\
\text { management measures, laying the } \\
\text { time-tested foundation of development. }\end{array}$ \\
\hline
\end{tabular}

It is worth mentioning that the institutional practices of LeEco's organizational ecology can be classified into four types: implementation, incentive, communication, and cultural mechanisms. The implementation and incentive mechanisms have specific executive methods and requirements, in being rigid mechanisms with detailed rules and regulations. However, the communication and cultural mechanisms are abstract, flexible mechanisms with spiritual effects on individuals and organizations. Therefore, the institutional practices of LeEco essentially accord with ancient Chinese Taoist values of "hardness with softness" and "Yin and Yang symbiosis". From the case study, we summarize the sustainable development path of LeEco's organizational ecology in Table 9. 
Table 9. LeEco ecology growth framework based on institutional logic.

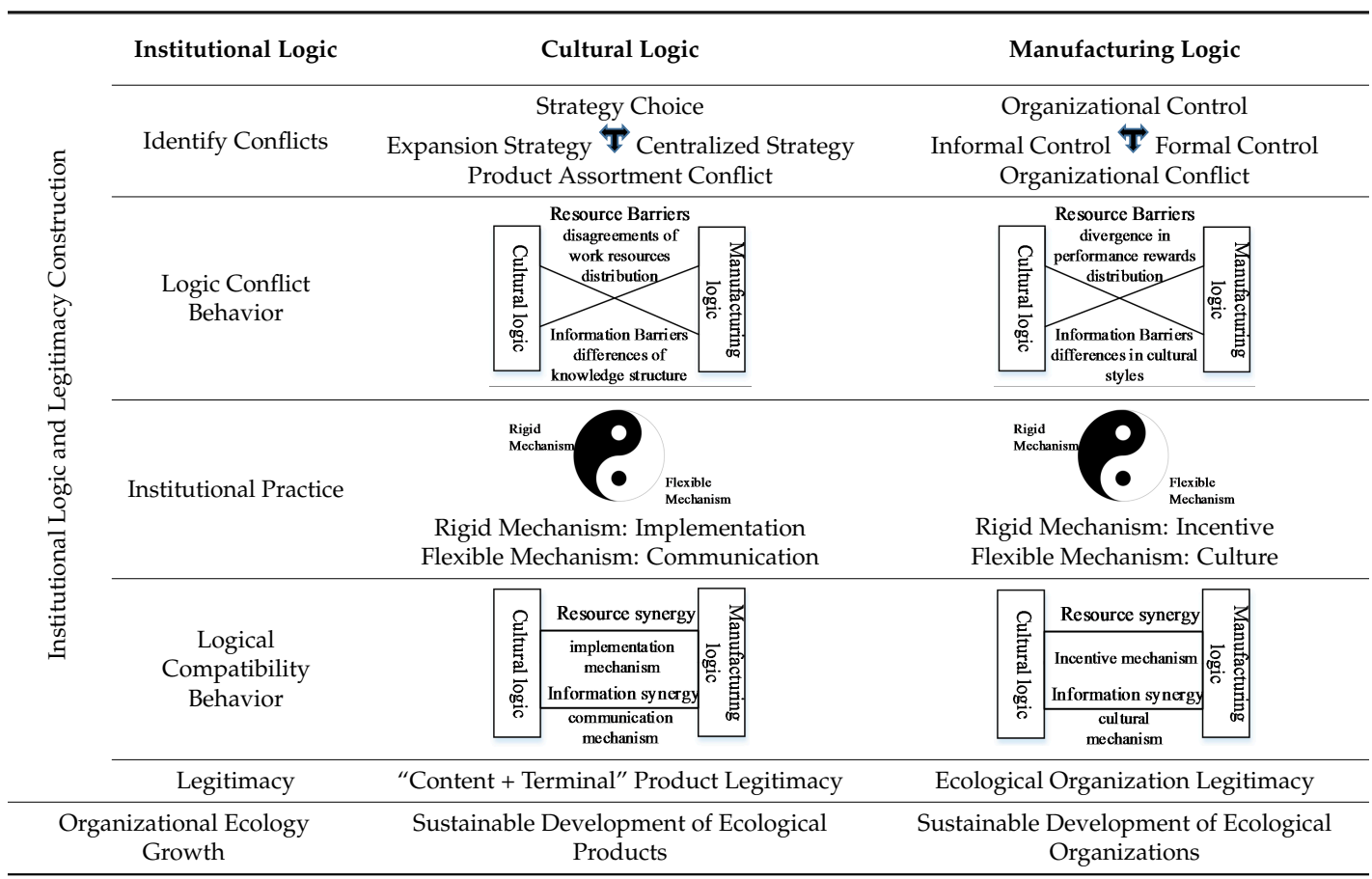

\section{Conclusions}

Previous research on the sustainable development of organizational ecology mainly focuses on the macro descriptions and the analysis of influencing factors [9]. The previous research has been set mostly in traditional industries [16]; this article, however, explores a brand-new Internet-based enterprise. We conduct a case study of LeEco, a Chinese Internet company with typical ecology, and explained the causes and path for the organizational ecological growth of a single company from the perspective of institutional logic. The theoretical contributions are concluded into three aspects.

(1) This paper opens up the "black box" of sustainable development of organizational ecology at the micro level, which contributes to the theory of organizational ecology. It analyzes LeEco from the perspective of institutional logic and has the following findings. Firstly, resource barriers and information barriers are the main factors affecting the organizational ecology growth of Internet enterprises. Secondly, constructions of product legitimacy and organizational legitimacy are essential for Internet enterprises to sustainably develop their organizational ecologies. Thirdly, a series of efficient institutional practices are required in the process of breaking the barriers to legitimacy construction. In the case of LeEco, cultural logic and manufacturing logic in organizational ecology cause some organizational conflicts. Not with standing conflict type, conflicts can be considered either resource conflicts or information conflicts. Accordingly, enterprises need to find mechanisms for breaking barriers in institutional practice. The results are directly manifested in the constructions of product legitimacy and organizational legitimacy in organizational ecology. Moreover, this article studies the sustainable development of organizational ecology from the perspective of institutional logic, which theoretically links the institutional logic, the legitimacy and organizational ecology together. Based on this, we have found out the importance of legitimacy acquisition for the sustainable development of organizational ecology. Simultaneously, this study expands the research space of organizational ecology theory from the perspective of institutional theory, providing valuable references for the future research.

(2) This paper built a sustainable development model for organizational ecology of Internet enterprises based on the perspective of institutional logic. This model contributes to the growth of Internet enterprises. The model built in this article identifies institutional logics, analyzes logic conflicts, 
implements institutional practice, constructs legitimacy, and promotes growth of the institution's ecology (see Figure 5). The model describes the path for growth of the organizational ecology of Internet companies at the micro level: The first step in each organization is to identify institutional logic in organizational ecology; the second step is to analyze conflicts among institutional logic and apply the rigid and flexible mechanisms to resolve conflicts; the third step is to promote the growth of organizational ecology through the construction of legitimacy in the organizational ecology. The model also shows that, the main restricting factors are the resource and information barriers in the process of the sustainable development of organizational ecology. Therefore, we need to resolve the problem through the continuous innovation of the institutional practice. The model has accomplished the closed-loop research of discovery, analysis and resolution of the problem. Meanwhile, the model used is from the Chinese Internet industry, and fills in gaps in the growth issues of Internet enterprises.

(3) This research proposed a new solution of institutional practice for multi-institutional conflicts under complicated institutional situations, which contributes to the theory of institutional logic. The survival and growth of the organization are affected by organizational pressure caused by incompatibility and conflicts in multi-institutional logic [72]. This paper found a new approach for institutional practice in the case study of LeEco: the rigid/flexible mechanism (the implementation mechanism, the communication mechanism, the incentive mechanism, and the cultural mechanism). This mechanism echoes ancient Chinese Taoist philosophy of Yin and Yang symbiosis, which emphasizes the importance of hardness with softness and collaboration. For LeEco, implementation and incentive mechanisms are rigid, breaking through the resource barriers of organizational ecology, while the communication and cultural mechanisms are flexible, breaking through information barriers in organizational ecology. Only when rigid and flexible mechanisms work together in an organization's ecology can they construct product and organizational legitimacy and promote sustainable development of organizational ecologies.

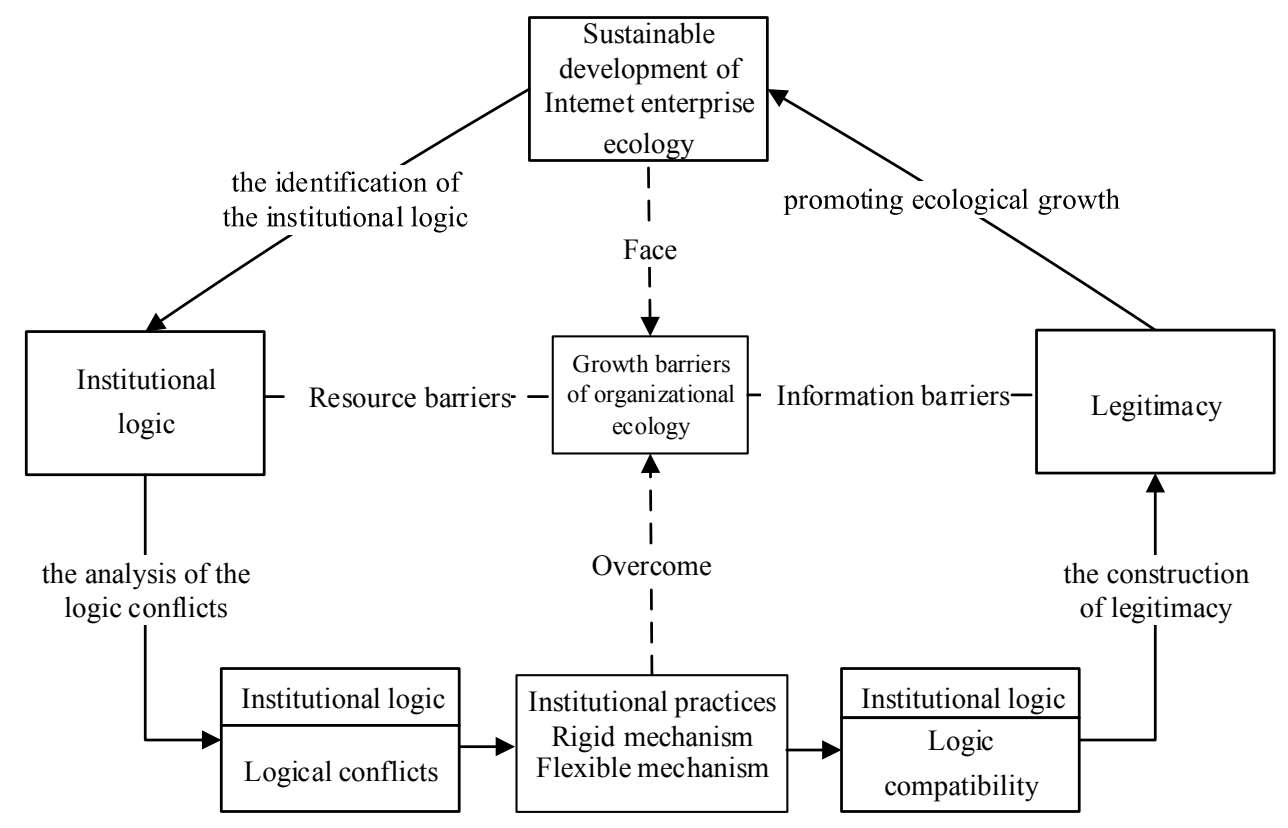

Figure 5. Sustainable development model of organizational ecologies in Internet enterprises based on institutional logic theory.

The conclusion of this article provides three insights into the practice of Internet enterprises. (1) This paper proposes a clear growth path for Internet enterprises according to the sustainable development model of organizational ecologies, based on LeEco's case. It can solve the problem of integration development of multiple industries. Internet enterprises need to identify their own 
institutional logic deeply in the future development, analyze conflicts and resolve them through the continuous innovation of the institutional practice to obtain legitimacy within the organization. This case study is able to provide experience for organizational ecology growth of other Internet enterprises. (2) Sustainable development of organizational ecologies in the Internet enterprises cannot be achieved unless the barriers in the way are removed. Therefore, the companies should identify multi-institutional logics and improve the practical ability in changing institutional logic conflicts into institutional compatibility. (3) The rigid and flexible mechanism (the communication mechanism, the implementation mechanism, the incentive mechanism and the cultural mechanism) proposed in this article provides a feasible management method for the Internet enterprises to solve organizational conflicts caused by institutional logic. Internet enterprises should adopt the rigid mechanism by facing the resource barriers, such as the implementation or incentive mechanism. Correspondingly, to resolve the information barrier, the Internet should implement the flexible mechanism such as the communication or cultural mechanism acting on the cultural level of the organization. Internet enterprises should apply a rigid and flexible mechanism according to the actual situation of the organization.

There are some limitations in this paper, with two aspects remaining for future research: (1) This article uses LeEco because of its large-scale Internet background and most obvious ecology characteristics. Most importantly, it has abundant human resources and the ability to resolve the barriers in the process of the sustainable development of organizational ecology. However, how should we build sustainable development mechanisms for the small and medium-sized Internet companies? We will further collect and analyze other cases in future work to complete and improve the conclusions of this study. (2) The research adopts the method of an exploratory case study without carrying out empirical tests, and builds a model based on the interview data and theoretical analysis. Our following research will perform quantitative tests on the model.

Acknowledgments: This study was funded by the National Science Foundation of China (Grant Number: 41421001, 41201412), Featured Institute Construction Services Program (TSYJS03) and Beijing Municipal Science and Technology Project (Z161100002616028).

Author Contributions: As the primary author, Hao Ren initiated the case study, performed the analysis, and wrote the paper. Rongrong Wang contributed in structuring and editing the paper, and proofreading the manuscript. Suopeng Zhang and An Zhang supervised and provided advice on this case study.

Conflicts of Interest: The authors declare no conflicts of interest.

\section{References}

1. Dcruz, B.; Hameed, S. Internet Development Opportunities for Small to Medium Sized Enterprises in Ukraine. Life Sci. J. 2012, 9, 41-47.

2. Zeng, J.; Glaister, K.W. Competitive dynamics between multinational enterprises and local internet platform companies in the virtual market in China. Br. J. Manag. 2015, 27, 479-496. [CrossRef]

3. Moore, B. Social Origins of Dictatorship and Democracy: Lord and Peasant in the Making of the Modern World; Beacon Press: Biddeford, ME, USA, 1993.

4. Polefka, S.; Sutton-Grier, A.E. Making ecosystem services part of business as usual in federal governance. Front. Ecol. Environ. 2016, 14, 175. [CrossRef]

5. Dupont, D.; Beresniak, A.; Sundgren, M.; Schmidt, A.; Ainsworth, J.; Coorevits, P.; Kalra, D.; Dewispelaere, M.; De Moor, G. Business analysis for a sustainable, multi-stakeholder ecosystem for leveraging the Electronic Health Records for Clinical Research (EHR4CR) platform in Europe. Int. J. Med. Inf. 2017, 97, 341-352. [CrossRef] [PubMed]

6. Hannan, M.T.; Carroll, G. Dynamics of Organizational Populations: Density, Legitimation, and Competition; Oxford University Press: Oxford, UK, 1992; pp. 355-367.

7. Abbott, K.W.; Green, J.F.; Keohane, R.O. Organizational ecology and institutional change in global governance. Int. Organ. 2016, 70, 247-277. [CrossRef]

8. Reimer, S.; Chapman, M.; Janzen, R.; Watson, J.; Wilkinson, M. Christian Churches and Immigrant Support in Canada: An Organizational Ecology Perspective. Rev. Relig. Res. 2016, 58, 495-513. [CrossRef] 
9. Todd, P.R.; Javalgi, R.G.; Grossman, D. Understanding the characteristics of the growth of SMEs in B-to-B markets in emerging economies: An organizational ecology approach. J. Bus. Ind. Mark. 2014, 29, 295-303. [CrossRef]

10. Cui, Y.; Jiao, J.; Jiao, H. Technological innovation in Brazil, Russia, India, China, and South Africa (BRICS): An organizational ecology perspective. Technol. Forecast. Soc. Chang. 2016, 107, 28-36. [CrossRef]

11. Frick, B.; Wallbrecht, B. Infant Mortality of Professional Sports Clubs: An Organizational Ecology Perspective. Jahrbücherfür Nationalökonomie und Statistik 2012, 232, 360-389.

12. Freeman, J.; Larsen, E.R.; Lomi, A. Why is there no cannery in 'Cannery Row'? Exploring a behavioral simulation model of population extinction. Ind. Corp. Chang. 2012, 21, 99-125. [CrossRef]

13. Hiatt, S.R.; Sine, W.D.; Tolbert, P.S. From Pabst to Pepsi: The deinstitutionalization of social practices and the creation of entrepreneurial opportunities. Adm. Sci. Q. 2009, 54, 635-667. [CrossRef]

14. Wenting, R.; Frenken, K. Firm entry and institutional lock-in: An organizational ecology analysis of the global fashion design industry. Ind. Corp. Chang. 2011, 20, 1031-1048. [CrossRef]

15. Andersson, F.O.; Ford, M.R. Social entrepreneurship through an organizational ecology lens: Examining the emergence and evolution of the voucher school population in Milwaukee. VOLUNTAS Int. J. Volunt. Nonprofit Organ. 2016, 27, 1760-1780. [CrossRef]

16. $\mathrm{Xu}, \mathrm{Y}$. Modeling the adoption of social media by newspaper organizations: An organizational ecology approach. Telemat. Inform. 2017, 34, 151-163. [CrossRef]

17. Friedland, R.; Alford, R.R. Bringing Society Back in: Symbols, Practices and Institutional Contradictions. In The New Institutionalism in Organizational Analysis; Powell, W.W., Dimaggio, P.J., Eds.; University of Chicago Press: Chicago, IL, USA, 1991; pp. 232-263.

18. Thornton, P.H. Markets from Culture: Institutional Logics and Organizational Decisions in Higher Education Publishing; Stanford University Press: Redwood City, CA, USA, 2004.

19. Dunn, M.B.; Jones, C. Institutional logics and institutional pluralism: The contestation of care and science logics in medical education, 1967-2005. Adm. Sci. Q. 2010, 55, 114-149. [CrossRef]

20. Baum, J.A.C.; Oliver, C. Toward an institutional ecology of organizational founding. Acad. Manag. J. 1996, 39, 1378-1427. [CrossRef]

21. Eisenhardt, K.M.; Graebner, M.E. Theory building from cases: Opportunities and challenges. Acad. Manag. J. 2007, 50, 25-32. [CrossRef]

22. Hannan, M.T.; Carroll, G.R.; Dundon, E.A.; Torres, J.C. Organizational evolution in a multinational context: Entries of automobile manufacturers in Belgium, Britain, France, Germany, and Italy. Am. Sociol. Rev. 1995, 60, 509-528. [CrossRef]

23. Campbell, D.T. Reforms as experiments. Am. Psychol. 1969, 24, 409. [CrossRef]

24. Hannan, M.T.; Freeman, J. The population ecology of organizations. Am. J. Soc. 1977, 82, 929-964. [CrossRef]

25. Liu, S.; Wu, H. The Ecology of Organizational Growth: Chinese Law Firms in the Age of Globalization. Am. J. Soc. 2016, 122, 798-837. [CrossRef]

26. Manser, K.; Hillebrand, B.; Driessen, P.H.; Ziggres, G.W.; Bloemer, J. Activity sets in multi-organizational ecologies: A project-level perspective on sustainable energy innovations. Technol. Forecast. Soc. Chang. 2015, 90, 444-455. [CrossRef]

27. Hannan, M.T. A Model of Competitive and Institutional Processes in Organizational Ecology; Cornell University: New York, NY, USA, 1986.

28. Hannan, M.T.; Freeman, J. Where do organizational forms come from? Sociological forum. Kluwer Acad. Publ. 1986, 1, 50-72.

29. Cattani, G.; Ferriani, S. A core/periphery perspective on individual creative performance: Social networks and cinematic achievements in the Hollywood film industry. Organ. Sci. 2008, 19, 824-844. [CrossRef]

30. McEvily, B.; Jaffee, J.; Tortoriello, M. Not all bridging ties are equal: Network imprinting and firm growth in the Nashville legal industry, 1933-1978. Organ. Sci. 2012, 23, 547-563. [CrossRef]

31. Carroll, G.R.; Hannan, M.T. Density delay in the evolution of organizational populations: A model and five empirical tests. Adm. Sci. Q. 1989, 34, 411-430. [CrossRef]

32. Barnett, W.P.; Amburgey, T.L. Do Larger Organizations Generate Stronger Competition? Graduate School of Business, University of Wisconsin-Madison: Madison, WI, USA, 1989.

33. Barnett, W.P. The dynamics of competitive intensity. Adm. Sci. Q. 1997, 42, 128-160. [CrossRef] 
34. Hannan, M.T. Inertia, density and the structure of organizational populations: Entries in European automobile industries, 1886-1981. Organ. Stud. 1997, 18, 193-228. [CrossRef]

35. Barron, D.N. The structuring of organizational populations. Am. Sociol. Rev. 1999, 64, 421-445. [CrossRef]

36. Lomi, A.; Larsen, E.R.; Freeman, J.H. Things change: Dynamic resource constraints and system-dependent selection in the evolution of organizational populations. Manag. Sci. 2005, 51, 882-903. [CrossRef]

37. Lounsbury, M. A tale of two cities: Competing logics and practice variation in the professionalizing of mutual funds. Acad. Manag. J. 2007, 50, 289-307. [CrossRef]

38. Thornton, P.H.; Ocasio, W. Institutional logics. Sage Handb. Organ. Inst. 2008, 840, 99-128.

39. Hoffman, A.J. Institutional evolution and change: Environmentalism and the US chemical industry. Acad. Manag. J. 1999, 42, 351-371. [CrossRef]

40. Rao, H.; Monin, P.; Durand, R. Institutional change in Toque Ville: Nouvelle cuisine as an identity movement in French gastronomy. Am. J. Social. 2003, 108, 795-843. [CrossRef]

41. Thornton, P.H.; Ocasio, W. Institutional logics and the historical contingency of power in organizations: Executive succession in the higher education publishing industry, 1958-1990. Am. J. Sociol. 1999, 105, 801-843. [CrossRef]

42. Thornton, P. Mapping Poverty and Livestock in the Developing World; ILRI: Nairobi, Kenya, 2002.

43. Maguire, S.; Hardy, C.; Lawrence, T.B. Institutional entrepreneurship in emerging fields: HIV/AIDS treatment advocacy in Canada. Acad. Manag. J. 2004, 47, 657-679. [CrossRef]

44. Marquis, C.; Lounsbury, M. Vive la résistance: Competing logics and the consolidation of US community banking. Acad. Manag. J. 2007, 50, 799-820. [CrossRef]

45. Cobb, J.A.; Wry, T.; Zhao, E.Y. Funding financial inclusion: Institutional logics and the contextual contingency of funding for microfinance organizations. Acad. Manag. J. 2016, 59, 2103-2131. [CrossRef]

46. Ocasio, W.; Radoynovska, N. Strategy and commitments to institutional logics: Organizational heterogeneity in business models and governance. Strateg. Organ. 2016, 14, 287-309. [CrossRef]

47. Zhu, Y.; Rooney, D.; Phillips, N. Practice-Based Wisdom Theory for Integrating Institutional Logics: A New Model for Social Entrepreneurship Learning and Education. Acad. Manag. Learn. Educ. 2016, 15, 607-625. [CrossRef]

48. Rueede, D.; Kreutzer, K. Legitimation work within a cross-sector social partnership. J. Bus. Ethics 2015, 128, 39-58. [CrossRef]

49. Scott, P. The Meanings of Mass Higher Education; McGraw-Hill Education (UK): London, UK, 1995.

50. Suchman, M.C. Managing legitimacy: Strategic and institutional approaches. Acad. Manag. Rev. 1995, 20, 571-610.

51. Barley, S.R. Building an institutional field to corral a government: A case to set an agenda for organization studies. Organ. Stud. 2010, 31,777-805. [CrossRef]

52. DiMaggio, P.; Powell, W.W. The iron cage revisited: Collective rationality and institutional isomorphism in organizational fields. Am. Sociol. Rev. 1983, 48, 147-160. [CrossRef]

53. North, D.C. Institutions, Institutional Change and Economic Performance; Cambridge University Press: Cambridge, UK, 1990.

54. Crawford, L.; Aitken, A.; Hassner-Nahmias, A. Project Management and Organizational Change; Project Management Institute, Inc.: Newtown Square, PA, USA, 2014.

55. Bruton, G.D.; Ahlstrom, D.; Li, H.L. Institutional theory and entrepreneurship: Where are we now and where do we need to move in the future? Entrep. Theory Pract. 2010, 34, 421-440. [CrossRef]

56. Spilker, G.; Koubi, V. The effects of treaty legality and domestic institutional hurdles on environmental treaty ratification. Int. Environ. Agreem. Politics Law Econ. 2016, 16, 223-238. [CrossRef]

57. Yin, R.K. Case Study Research: Design and Methods; Sage Publications: Thousand Oaks, CA, USA, 2013.

58. Patton, M.Q. How to Use Qualitative Methods in Evaluation; Sage publications: Thousand Oaks, CA, USA, 1987.

59. Glaser, B.G.; Strauss, A.L. The Discovery of Grounded Theory: Strategies for Qualitative Research; Transaction Publishers: Piscataway, NJ, USA, 2009.

60. Pan, S.L.; Tan, B. Demystifying case research: A structured-pragmatic-situational (SPS) approach to conducting case studies. Inf. Organ. 2011, 21, 161-176. [CrossRef]

61. Thornton, P.H.; Ocasio, W.; Lounsbury, M. The Institutional Logics Perspective: A New Approach to Culture, Structure, and Process; Oxford University Press on Demand: Oxford, UK, 2012. 
62. Child, J. Organizational structure, environment and performance: The role of strategic choice. Sociology 1972, 6, 1-22. [CrossRef]

63. Cardinal, L.B.; Sitkin, S.B.; Long, C.P. Balancing and rebalancing in the creation and evolution of organizational control. Organ Sci. 2004, 15, 411-431. [CrossRef]

64. Kirsch, L.S. Portfolios of control modes and IS project management. Inf. Syst. Res. 1997, 8, $215-239$. [CrossRef]

65. Kirsch, L.J.; Ko, D.G.; Haney, M.H. Investigating the antecedents of team-based clan control: Adding social capital as a predictor. Organ. Sci. 2010, 21, 469-489. [CrossRef]

66. Kirsch, L.J.; Sambamurthy, V.; Ko, D.G.; Purvis, R.L. Controlling information systems development projects: The view from the client. Manag. Sci. 2002, 48, 484-498. [CrossRef]

67. Rustagi, S.; King, W.R.; Kirsch, L.J. Predictors of formal control usage in IT outsourcing partnerships. Inf. Syst. Res. 2008, 19, 126-143. [CrossRef]

68. Taylor, S.A.; Baker, T.L. An assessment of the relationship between service quality and customer satisfaction in the formation of consumers' purchase intentions. J. Retail. 1994, 70, 163-178. [CrossRef]

69. Espinosa, A.; Lerch, J.; Kraut, R. Explicit vs. implicit coordination mechanisms and task dependencies: One size does not fit all. In Team Cognition: Process and Performance at the Inter-Individual and Intra Individual Level; Salas, E., Fiore, S.M., Florian, J., Bowers, C.A., Eds.; American Psychological Association: Washington, DC, USA, 2002; pp. 107-129.

70. McPherson, C.M.; Sauder, M. Logics in action managing institutional complexity in a drug court. Adm. Sci. Q. 2013. [CrossRef]

71. Lawrence, T.B.; Suddaby, R. 1.6 institutions and institutional work. In Handbook of Organization Studies; Clegg, S.R., Hardy, C., Lawrence, T.B., Nord, W.R., Eds.; Sage: London, UK, 2006; pp. 215-254.

72. Greenwood, R.; Raynard, M.; Kodeih, F.; Micelotta, E.R.; Lounsbury, M. Institutional complexity and organizational responses. Acad. Manag. Ann. 2011, 5, 317-371. [CrossRef]

(C) 2017 by the authors. Licensee MDPI, Basel, Switzerland. This article is an open access article distributed under the terms and conditions of the Creative Commons Attribution (CC BY) license (http://creativecommons.org/licenses/by/4.0/). 